\title{
Double inferior vena cava with three shunts: a rare anomaly with important implications for surgeons
}

\author{
W. Chaijaroonkhanarak ${ }^{1}$, W. Pannangrong ${ }^{1,2}$, J. Umka Welbat ${ }^{1,2,3}$, M. Namking ${ }^{1}$, \\ K. Khamanarong ${ }^{1}$, P. Prachaney ${ }^{1}$ \\ ${ }^{1}$ Department of Anatomy, Faculty of Medicine, Khon Kaen University, Khon Kaen, Thailand \\ ${ }^{2}$ Center for Research and Development of Herbal Health Products, Khon Kaen University, Khon Kaen, Thailand \\ ${ }^{3}$ Neuroscience Research and Development Group, Khon Kaen University, Khon Kaen, Thailand
}

[Received: 16 September 2016; Accepted: 25 October 2016]

\begin{abstract}
Inferior vena cava (IVC) is the largest single vein that collects systemic venous blood from the lower part of the body except the gut and drains into the right atrium. Double IVC is a rare anomaly in humans and usually is discovered incidentally during the interventional radiological procedures or routine cadaveric dissection. Here we report a rare case of unusual observations in an adult female Thai cadaver with a duplicated left IVC with three short venous shunts and a variant pattern of the hemiazygos vein. Also included in this case was the presence of unilateral double renal vein on the right kidney. This type of anatomic variation of the great vein has never been reported before. A detailed description of these variations is useful and essential for the surgeons during approaching the retroperitoneal region. (Folia Morphol 2017; 76, 2: 307-311)
\end{abstract}

Key words: inferior vena cava, supracardinal veins, venous shunt

\section{INTRODUCTION}

In human, the inferior vena cava (IVC) is typically a single vein located on the posterior abdominal wall in the retroperitoneal space of the abdomen. It is formed by the union of the right and left common iliac veins in front of the $5^{\text {th }}$ lumbar vertebra. This largest vein and its tributaries normally return deoxygenated blood from the lower part of the body except the gut. It then ascends cranially along the right side of the vertebral column with the aorta running laterally on the left and passing through the diaphragm to drain into the right atrium on its posterior side [23]. Variations of IVC may occur due to many complicated transformation processes during embryonic life $[15,19]$. Anatomical variation of the
IVC occurs in $0.4-4 \%$ of the population [14]. Among the abnormalities related to the formation of the IVC, the double IVC (DIVC) was the most common anatomic variation [3]. We report here a case of DIVC with three short venous shunts and a variant pattern of the hemiazygos vein in a Thai cadaver. The relevant literature, the embryogenesis of the IVC related to this rare anatomical variant, and the clinical significance were reviewed and discussed.

\section{CASE REPORT}

During routine anatomical dissection for medical students in the Department of Anatomy, Faculty of Medicine, Khon Kaen University, an anatomical variation of the IVC with associated variations were

Address for correspondence: Associate Prof. Dr. W. Chaijaroonkhanarak, Department of Anatomy, Faculty of Medicine, Khon Kaen University, Khon Kaen, 40002 Thailand, tel: +66868561124; fax: +66 43348 381, e-mail: cwunnee@kku.ac.th 


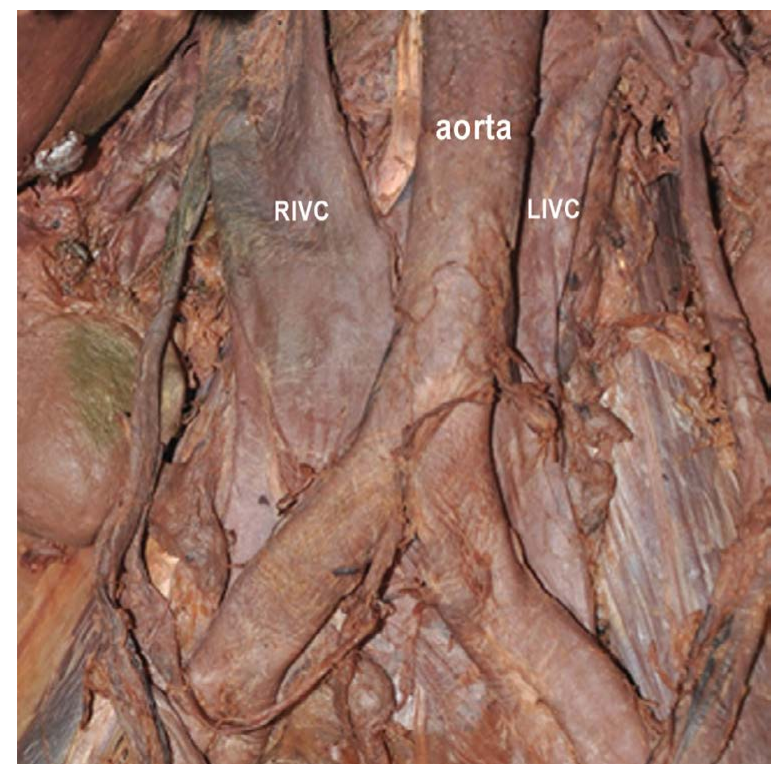

Figure 1. Dissection of retroperitoneal region showing the anatomical variation of double inferior vena cava on both sides of the abdominal aorta; RIVC — right inferior vena cava; LIVC left inferior vena cava.

observed in a 45-year-old Thai female cadaver. The retroperitoneal region including all of the vessels concerned was carefully dissected. The measuring instrument used was sliding Vernier calliper.

This dissection was approved by the Human Ethics Committee of Khon Kaen University, Khon Kaen, Thailand (Approval No. HE 571314).

\section{OBSERVATIONS}

In the retroperitoneal region, DIVC was detected unexpectedly on both sides of the abdominal aorta (Fig. 1). The abdominal aorta was cut and reflected to expose the anomalous venous channels (Fig. 2A). All the anomalies were presented by outline drawing in Figure $2 \mathrm{~B}$ for the clarity.

At the confluence of the left internal iliac and external iliac veins, a duplicated left IVC was found. Its dimensions were $12.73 \mathrm{~cm}$ in length and $0.68 \mathrm{~cm}$ in diameter. It passed upward posterior to the left side of the abdominal aorta to join the left renal vein (Fig. 2). After receiving blood from the left renal vein, the left IVC continued to become the hemiazygos vein. It travelled upward medially passing in front of the body of the $8^{\text {th }}$ thoracic vertebra to join the azygos vein at the right side of the intervertebral disc between the $7^{\text {th }}-8^{\text {th }}$ thoracic vertebrae. The azygos vein then received the superior intercostal veins before terminating into the right atrium. The left suprarenal vein
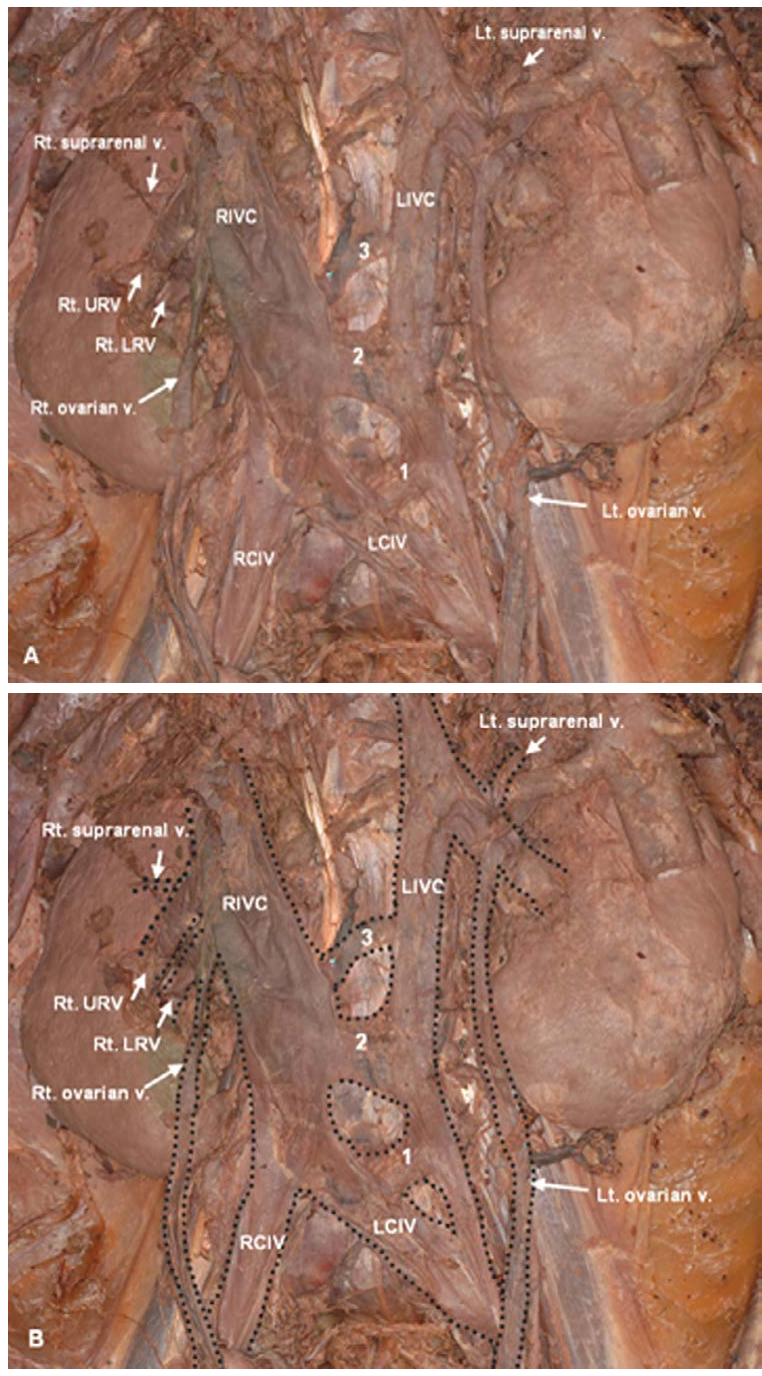

Figure 2. A. Double inferior vena cava and the three short venous shunts. The double right renal veins emerged from the hilum of the kidney to enter the right inferior vena cava. The right suprarenal renal vein drained into the right upper renal vein. The right ovarian vein drained into the junction of the right lower renal vein and then to the right inferior vena cava; $B$. Outline drawing of the anatomical variations of the panel A; URV — upper renal vein; LRV — lower renal vein; RCIV — right common iliac vein; LCIV — left common iliac vein; RIVC — right inferior vena cava; LIVC — left inferior vena cava.

and the left ovarian vein drained into the left renal vein as usual.

The right IVC was formed by the joining of the left and right common iliac veins as usual but its route deviated from the centrally lined abdominal aorta when running up to the right kidney. The length of the right abdominal IVC was $13.5 \mathrm{~cm}$ and the diameter was $1.4 \mathrm{~cm}$.

Three short venous shunts were noticed (Fig. 2A, B). The $1^{\text {st }}$ shunt was $1.92 \mathrm{~cm}$ in length and connected the left common iliac vein and the left IVC. The $2^{\text {nd }}$ 
and $3^{\text {rd }}$ shunts, $1.67 \mathrm{~cm}$ and $1.25 \mathrm{~cm}$ in length, respectively, connected the right and the left IVC.

Other associated anomalies were the two right renal (upper and lower) veins merging from the renal hilum to enter the right IVC. The right suprarenal renal vein drained into the right upper renal vein whereas the right ovarian vein drained into the venous angle formed by the right lower renal vein and the right IVC.

\section{DISCUSSION}

The DIVC was first described in a male cadaver by Lucas [13]. The prevalence of DIVC is estimated between $0.2 \%$ and $3 \%$ [4].

Ang et al. [1] reviewed and analysed 41 published articles about DIVC between 2000 and 2011 and found that there were 53 (31 males, 21 females, and 1 unknown) cases of DIVC from 18 countries and the incidence of DIVC was slightly higher in males than in the females. In addition, we have found 5 more DIVC cases in the same period of 2000-2011, which have not been included in the review of Ang et al. [1]. Artico et al. [3] detected a case of DIVC in an adult male patient during a computed tomography (CT)-scanning for follow-up of pancreatic cancer. Kumar [10] reported a case of an adult male cadaver having the DIVC, which ascended to join the left renal vein before connecting to the right IVC. Likewise, Xue et al. [24] found a Japanese male cadaver, having a DIVC, in that the left IVC coalesced with the left renal vein and finally ran across in front of the abdominal aorta and drained into the right IVC. Two cases of DIVC were found during renal transplantation: Kennealey et al. [9] found a DIVC in a female living renal transplant donor and Raza et al. [17] found a DIVC in a male deceased organ donor. Discovery of the anomalous vessels during transplantation caused prolongation of the operative time to re-design the procedure for safety outcomes.

After extensive literature survey, we have found 13 additional cases ( 6 males and 7 females) of DIVC from 2012 to 2015: A case of DIVC was found during phlebography for the treatment of a pulmonary thromboembolism from multiple traumas in a male patient [18]. Loo and Jhummon-Mahadnac [12] reported 2 cases of duplicated left IVC in Australian, 1 case was a female cadaver and the other case a living adult male who underwent a staging CT-scan for preoperative work-up. In both cases, duplicated left IVC began at the left common iliac vein, joining the left renal vein, and then crossed the abdominal aorta anteriorly to enter the right IVC. Hayashi et al. [7] reported 3 cases of DIVC ( 2 males and a female) in Japanese cadavers and described three types of the flow pattern of DIVC. In addition to the literature review of 2000-2011, Ang et al. [1] reported 3 more cases of DIVC in female patients investigated by abdominal CT scan in New Zealand. Tanka [22] reported 2 cases ( 1 case each of male and female) of DIVC in Albania while CT imaging of the abdominal region. More recently, Kumar et al. [11] reported an incidental finding of DIVC in an Indian female patient on CT abdominal angiography. Furthermore, Polguj et al. [16] detected a case of DIVC by CT examination in a male patient with endovascular repair for abdominal aortic aneurysm. This finding was similar to the present case in that the left renal vein joined with the left IVC and continued as the hemiazygos vein. As can be seen in those literature surveys, more variations of the IVC have been increasingly detected along with the advance of many vascular imaging techniques.

Our DIVC case reported here is unique and different from all of the cases mentioned above, in that the left side IVC continued to become the hemiazygos vein after joining the left renal vein and the 3 shunts. Double right renal vein and the 3 shunts associated with DIVC have never been reported before.

Although the clear aetiology of DIVC is still unknown, understanding of the complicated embryogenesis of the venous system is helpful to understand the vascular variation reported here. The IVC is formed by regression, anastomosis and replacement of the foetal venous blood system during $4^{\text {th }}-8^{\text {th }}$ week of gestation [8, 19, 21]. Initially, there were composed of the three sets of paired veins; the posterior cardinal veins, the subcardinal veins, and the supra cardinal veins, which are formed at the retroperitoneal region. The posterior cardinal veins primarily collect the caudal half of venous blood in the earliest embryo development and then regress. During the $5^{\text {th }}$ and $8^{\text {th }}$ week, while the posterior cardinal veins gradually relapse, the bilateral subcardinal veins develop and become dominant at $7^{\text {th }}$ week. By the $8^{\text {th }}$ week, the posterior cardinal veins become gradually degenerated, and then superseded by the supracardinal veins [8]. Numerous anastomotic vessels connect the each side of subcardinal veins and posterior cardinal veins including the supracardinal veins. As the subcardinal veins remodelled, the posterior cardinal veins obliterated. The posterior cardinal veins degenerate almost completely and remain only 


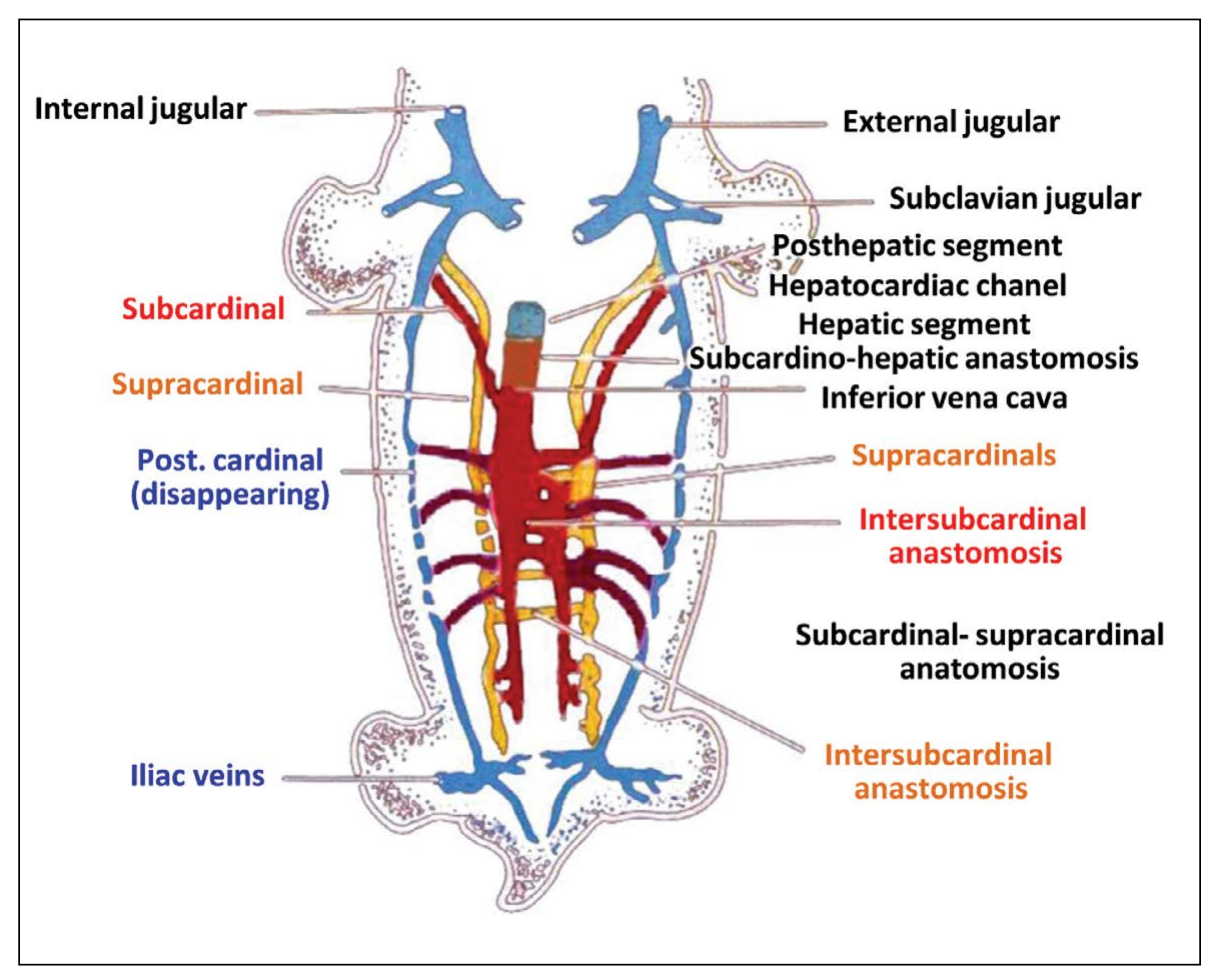

Figure 3. Remodelling and anastomosis of the three sets of primordial paired veins during embryogenesis to yield the final composition of the inferior vena cava (reproduced from Figure 4, In: Kellman et al. 1988; with permission from The Radiological Society of North America, RSNA).

as the common iliac vein and the caudal most sacral portion of the IVC. The right supracardinal vein anastomoses with the right subcardinal vein to form an infrarenal segment of the IVC whereas the lower portion of the left supracardinal vein obliterated as showed in Figure 3 [8]. Therefore, the double IVC observed in the present case might have resulted from the persistence of the caudal part of both left and right supracardinal veins. The $1^{\text {st }}$ venous shunt connected between the left common iliac vein and the left IVC in the present case might be a remnant of the venous anastomosis between the left supracardinal vein and the left posterior cardinal vein. In contrast, the persistence of the intersupracardinal anastomosis during remodelling may yield the $2^{\text {nd }}$ and $3^{\text {rd }}$ shunts in the present case.

The occurrence of DIVC is generally asymptomatic, the presence of this aberrant venous anatomy may have significant clinical implications to the radiologists, surgeons, etc. The potential for misdiagnosis on imaging may occur, leading to unnecessary treatment [2]. The surgeons should be aware of such variation of the IVC when performing surgical procedures in retroperitoneal region such as laparoscopic nephrectomy or donor nephrectomy $[6,20]$. When attempting cava filtration, DIVC patient may require placement of a caval filter into each vessel in order to avoid the embolism [5]. DIVC is also a risk factor for formation of thrombosis back pain and anomalous circulation of blood to the heart as a consequence of changes in blood flow [21]. In addition, the DIVC can increase a risk of vascular injury during retroperitoneal procedures leading to life-threatening $[6,9]$. Therefore, this asymptomatic anomaly has to be known prior to precede any abdominal surgery and sufficient preoperative planning is required to avoid an unexpected iatrogenic complication during the operation.

\section{CONCLUSIONS}

In conclusion, this is the first report of anatomic variation of DIVC with 3 shunts, associated with the continuation of left IVC to become the hemiazygos vein and unilateral double renal veins. These congenital variants caused by an unusual embryological development, are essential for clinical manipulation particularly for the surgeons during approaching the retroperitoneal region and the radiologist to avoid misdiagnosis as pathologic appearance on CT imaging. 


\section{Acknowledgements}

The authors acknowledge Invited Professor Dr. Yukifumi Nawa, Research Affairs Office and Associate Professor Dr. Kittisak Sawanyawisuth, Department of Medicine, Faculty of Medicine, Khon Kaen University, for their excellent comments and suggestions for preparing the manuscript.

\section{REFERENCES}

1. Ang WC, Doyle T, Stringer MD. Left-sided and duplicate inferior vena cava: a case series and review. Clin Anat. 2013; 26(8): 990-1001, doi: 10.1002/ca.22090, indexed in Pubmed: 22576868.

2. Arisawa C, Kihara K, Fujii Y, et al. Possible misinterpretation on computed tomography of left inferior vena cava as retroperitoneal lymph node metastasis: a report of two cases. Int J Urol. 1999; 6(4): 215-218, indexed in Pubmed: 10226843.

3. Artico $M$, Lorenzini $D$, Mancini $P$, et al. Radiological evidence of anatomical variation of the inferior vena cava: report of two cases. Surg Radiol Anat. 2004; 26(2): 153-156, doi: 10.1007/s00276-003-0192-0, indexed in Pubmed: 14600789.

4. Bass JE, Redwine MD, Kramer LA, et al. Spectrum of congenital anomalies of the inferior vena cava: cross-sectional imaging findings. Radiographics. 2000; 20(3): 639-652, doi: 10.1148/radiographics.20.3.g00ma09639, indexed in Pubmed: 10835118.

5. Cheng D, Zangan SM. Duplication of the inferior vena cava in a patient presenting for IVC filter placement. J Vasc Access. 2010; 11(2): 162-164, indexed in Pubmed: 20175061.

6. Eldefrawy A, Arianayagam $M$, Kanagarajah $P$, et al. Anomalies of the inferior vena cava and renal veins and implications for renal surgery. Cent European J Urol. 2011; 64(1): 4-8, doi: 10.5173/ceju.2011.01.art1, indexed in Pubmed: 24578852.

7. Hayashi S, Naito M, Hirai S, et al. Proposal for a new classification of variations in the iliac venous system based on internal iliac veins: a case series and a review of double and left inferior vena cava. Anat Sci Int. 2013; 88(4): 183-188, doi: 10.1007/s12565-013-0182-1, indexed in Pubmed: 23709295.

8. Kellman GM, Alpern MB, Sandler MA, et al. Computed tomography of vena caval anomalies with embryologic correlation. Radiographics. 1988; 8(3): 533-556, doi: $10.1148 /$ radiographics.8.3.3380993, indexed in Pubmed: 3380993.

9. Kennealey P, Saidi R, Markmann J, et al. Duplicated inferior vena cava-something to consider in the evaluation of a living-donor renal transplant. Dialysis \& Transplantation. 2009; 38(10): 420-422, doi: 10.1002/dat.20363.
10. Kumar S. An anomaly of inferior vena cava: a rare case report. Kathmandu Univ Med J (KUMJ). 2006; 4(2): 253-255, indexed in Pubmed: 18603911.

11. Kumar $A V$, Kumar $A A$, Hussain $A$, et al. An uncommon encounter during temporary pacemaker implantation: a double inferior vena cava. Indian Heart J. 2016; 68: S216-S217, doi: 10.1016/j.ihj.2016.01.012.

12. Loo ZY, Jhummon-Mahadnac N. Double inferior vena cava: a rare but important anatomical variation. Int J Anat Res. 2013; 1: 174-177.

13. Lucas MF. A case of double inferior vena cava. J Anat. 1916; 51(Pt 1): 69-70, indexed in Pubmed: 17103805.

14. Mayo J, Gray R, St Louis E, et al. Anomalies of the inferior vena cava. AJR Am J Roentgenol. 1983; 140(2): 339-345, doi: 10.2214/ajr.140.2.339, indexed in Pubmed: 6336872.

15. Moore KL, Persaud TVN, Torchia MG. Early development of the heart and blood vessels. In: The Developing Human: Clinically Oriented Embryology. Saunders, Philadelphia, pp 2013: 290-295.

16. Polguj M, Szubert W, Topol M, et al. An unusual duplication of the inferior vena cava in a patient with endovascular repair for abdominal aortic aneurysm. Rom J Morphol Embryol. 2015; 56(2 Suppl): 875-878, indexed in Pubmed: 26429190.

17. Raza S, Farid S, Reddy M, et al. Duplication of the inferior vena cava. J Surg Case Rep. 2011; 2011(9): 10, doi: 10.1093/jscr/2011.9.10, indexed in Pubmed: 24950511.

18. Saad KR, Saad PF, Amorim CA, et al. Razuk Filho A Duplication of the inferior vena cava: case report and a literature review of anatomical variation. J Morphol Sci. 2012; 29: 60-64.

19. Schoenwolf GC, Bleyl SB, Brauer PR, et al. Primitive embryonic venous system in divided into vitelline, umbilical, and cardinal systems. In: Larsen's Human Embryology. Livingstone, Philadelphia, pp. 2009: 419-424.

20. Shingleton WB, Hutton M, Resnick MI. Duplication of inferior vena cava: its importance in retroperitoneal surgery. Urology. 1994; 43(1): 113-115, indexed in Pubmed: 8284871.

21. Spentzouris G, Zandian A, Cesmebasi A, et al. The clinical anatomy of the inferior vena cava: a review of common congenital anomalies and considerations for clinicians. Clin Anat. 2014; 27(8): 1234-1243, doi: 10.1002/ ca.22445, indexed in Pubmed: 25042045.

22. Tanka M. Report of two cases of double inferior vena cava with an emphasis on embryogenesis and clinical relevance. Int J Anat Var. 2014; 7: 77-79.

23. Woodburne RT, Burkel WE. The head and neck. In: Woodburn RT, (eds.). Essentials of Human Anatomy. 9th ed. Oxford University Press, New York. 1994: pp. 172-179.

24. Xue HG, Yang CY, Asakawa M, et al. Duplication of the inferior vena cava associated with other variations. Anat Sci Int. 2007; 82(2): 121-125, doi: 10.1111/j.1447073X.2006.00153.x, indexed in Pubmed: 17585569. 